\title{
UNA ENFERMEDAD CONTAGIOSA: LOS FANTASEOS SOBRE SOR JUANA
}

No es exagerado decir que en el siglo xx, y muy especialmente en su segunda mitad, la bibliografía sobre Sor Juana, como la bibliografía sobre Góngora, ha venido a ser cien veces más numerosa que la existente en 1898. La obra de ambos poetas sufrió un eclipse casi total a partir de la segunda mitad del siglo xviII. La gente dejó de interesarse en ellos, y entonces ellos se fueron esfumando hasta quedar convertidos en fantasmas, en flatus vocis. La cerrazón crítica cuajó en fórmulas: escritores disparatados, violentadores de nuestra lengua, ininteligibles, ;culteranos!; y, por la fuerza de la inercia, quienes hubieran podido ser lectores se atuvieron a las fórmulas y dejaron de acercarse a Góngora y a Sor Juana. (En la historia de la crítica literaria de lengua española no hay episodio de más bulto y más perduración que la "reacción neoclásica" contra el "mal gusto" del Barroco. Las fórmulas condenatorias de un Menéndez Pelayo no difieren mucho de las ya cuajadas más de cien años antes de él.)

Durante casi medio siglo, a partir de 1689, Sor Juana estuvo en todo el imperio español por encima de cualquiera de sus contemporáneos. Pero ya su ausencia en la Poética de Ignacio Luzán (1737) y en las notas del P. Francisco Xavier Alegre a su versión del Arte poética de Boileau indica claramente que Sor Juana ha dejado de tener lectores. En efecto, no hay nada suyo en el Parnaso español (1768-1778) de Juan José López de Sedano ni en las Poesías selectas castellanas (1807) de Manuel José Quintana. Y, en México, un Fernández de Lizardi y un Manuel Payno conocen ciertamente el nombre de la "célebre monja", pero no tienen idea de quién fue, y ni siquiera de la época en que vivió ${ }^{1}$.

En momentos en que el olvido es tan impresionante, entran en escena los críticos alemanes de la era romántica, la que marca realmente el inicio de los tiempos modernos. Fueron ellos, por ejemplo,

${ }^{1}$ Para Lizardi y Payno véase Francisco De LA MAZA, Sor Juana Inés de la Cruz ante la historia, México, 1980, pp. 334-337 y 362-364. (Abreviaremos en adelante: MAZA). Véase también A. Alatorre, introducción a la Juana de Asbaje de Amado Nervo, México, 1994, pp. 11-25. 
los redescubridores de los romances viejos y de los autos sacramentales. Y también de Sor Juana. Los primeros modernos que se acordaron de ella son Friedrich Buchholz en su Handbuch der spanischen Sprache und Literatur, Poetischer Theil (Berlin, 1804, pp. 423-426) y Friedrich Bouterwek en su Geschichte der Poesie und Beredsamkeit seit des Ende der dreizehnten Jarhundert (t. 3, Göttingen, también 1804, pp. 557-562). En estas obras enciclopédicas, germánicamente concienzudas, hay no sólo una noticia acerca de la "mexikanische Nonne", sino también (en español, sin traducción alemana) una breve antología de sus versos, que así, por primera vez desde 1725, volvieron a ver la luz del día.

Las noticias de Buchholz y Bouterwek son breves, pero no inexactas. Dicen "lo esencial”, y le hacen saber al posible interesado que los escritos de la monja están impresos. El interesado se las arreglará para conseguir los tres viejos tomos, en el último de los cuales -la Fama y Obras pósthumas (1700)- leerá la Vida del P. Diego Calleja y la Respuesta a Sor Filotea de la Cruz, que eran y siguen siendo las dos fuentes caudales de nuestros conocimientos sobre Sor Juana.

Es excepcional el caso de Ignacio Carrillo y Pérez, que a fines del siglo XVIII da señales de auténtico interés por la obra de Sor Juana y se muestra muy lastimado por el olvido en que yace; reconoce que las largas páginas que dedica a la escritora van contra la corriente, y que la obra en que las ha puesto no es el lugar más indicado para ellas; pero esto ha sido inevitable; reconoce también que "solas sus obras pueden informar cabalmente" sobre Sor Juana, pero de algo puede servir "un epítome de su vida". Dichosamente ese epítome existe, y es preciso que el lector lo conozca. Se refiere a la Vida del P. Calleja. Parece que en un momento pensó Carrillo aprovecharla sólo como base, y luego vio que lo mejor era reproducirla en su integridad, "pues en mudarle, quitarle o ponerle alguna voz, echaría un borrón en el papel que delineó tan docta pluma, y más quiero padecer la nota de copiante que la de ignorante presumido".

En tiempos de Carrillo no eran ya raras las enciclopedias, esas obras que compilan metódicamente "lo que se sabe" sobre un tema dado y, con mayor o menor objetividad, dicen o tratan de decir la "última palabra" sobre el asunto, el "estado de nuestros conocimientos". Los compiladores de enciclopedias suponen -probablemente con razón- que quien las consulta está más interesado en hechos (fecha y lugar de nacimiento y muerte, obras principales, etc.) que en juicios literarios. Por lo que toca a Sor Juana, he aquí los datos que conocemos:

1) El portugués frei João de São Pedro, que con el pseudónimo "Damião de Froes Perym” publicó un diccionario enciclopédico de

${ }^{2}$ No sabemos qué obra es ésa. Nos basamos en el artículo dedicado a "San Jerónimo, calle de" por José María Marroqui, La ciudad de México, México, 1901-1903, t. 3, pp. 22-36. 
mujeres ilustres en todos los tiempos y lugares (Theatro heroino, Abecedário histórico e Catálogo das mulheres illustres em armas, letras, acções heroicas $e$ artes liberaes... etc.), incluye en el primer tomo (Lisboa, 1736, pp. 447-457) una detallada noticia sobre la Monja de México, hecha totalmente a base de la Vida de Calleja, con aprovechamiento del Prólogo de Castorena a la Fama y Obras pósthumas ${ }^{3}$.

2) El abate Louis Moreri había publicado en $1674 \mathrm{su}$ Grand dictionnaire historique, uno de los precursores de la Encyclopédie de Diderot y D'Alembert. En esos tiempos las cosas ibéricas habían dejado de interesar a la Europa culta. Pero en 1753, o sea ochenta años después, el Grand dictionnaire, todavía aprovechable en el retrasado orbe hispánico, fue traducido por Joseph de Miravel y Casadevante "con amplíssimas adiciones... relativas a las coronas de España y Portugal, assí en el Antiguo como en el Nuevo Mundo". Y una de sus adiciones es el artículo sobre Sor Juana, hecho totalmente a base de la Vida de Calleja ${ }^{4}$.

3) Juan José de Eguiara y Eguren tenía terminada a mediados del siglo XVIII su Bibliotheca Mexicana, escrita en latín (porque la destinaba a un público internacional) y hecha para demostrarle al cáustico Deán Martí, con las relucientes armas de la bibliografía, que México no era un árido desierto en materia de letras, como Martí había dicho, sino que desde el principio hubo entre nosotros gran cantidad de escritores. En 1755 logró Eguiara ver impreso el voluminoso tomo primero, que comprende sólo las letras $A, B$ y $C$. El resto del magnum

3 Pero "Froes Perym" no está a salvo de las tentaciones de la fantasía. Dice por ejemplo que Sor Juana, al ver que no podía colarse "em hábitos de varão" en la Universidad, "voltava as iras contra a natureza, que pelo sexo lhe fizera inútil o juízo, pobre o engenho" (!). Por otra parte, afirma que la escritora "vivia... entre os applausos de uma Universidade con veneraçoens de sábia”, y que "o Arcebispo de México [i¿Aguiar y Seixas?!] repetia com gosto e ameúdo as occasioens de fallar com ella”. El Theatro heroino está en orden alfabético (Amalasunta rainha, Anastásia romana, Amalthea Sybilla..., Anna Comnena, Antónia Rodrigues, portuguesa, Annazinga, princesa de Angola..., Bernarda Ferreira de Lacerda, Blesilla romana, Cleópatra, Santa Catharina de Sena..., Christina Alexandra, rainha de Suécia..., Dido rainha, etc.). En el caso de otras escritoras, el autor enumera sus obras, pero aquí no menciona siquiera los dos primeros tomos de Sor Juana. Aparte de su biografía, lo único que le interesa es su Crisis sobre el sermón del Mandato del P. Vieira, y la Apologia de Vieira por "Sor Margarida Ignácia”.

${ }^{4}$ Gran Diccionario Histórico, o Miscelánea curiosa de la historia sagrada y profana... etc., Paris-Lyon, 1753, 10 ts.; el artículo sobre Sor Juana está en el t. 6, p. 331, y puede verse en MAZA, pp. 304-307. Hay en este artículo muchas omisiones, pero sólo dos errores, uno de ellos de poca monta: se lee que las lecciones de latín que el bachiller Olivas le dio a Sor Juana fueron veinticinco (según Calleja, fueron "solas veinte lecciones"; Sor Juana, en la Respuesta, cree que "no llegaron a veinte"); el otro error es más serio: pondera Miravel "lo díscolos que estuvieron entre sí" los aprobantes de la Inundación Castálida: ha entendido mal el texto de Calleja, según el cual los dos aprobantes hicieron frente común en la defensa de Sor Juana contra sus impugnadores. (La errónea aseveración de Miravel fue aceptada ciegamente por MAzA, p. 54). 
opus permaneció inédito hasta estos últimos años, con dos excepciones: los Prólogos a la Bibliotheca y la "ficha" Ioanna Agnes a Cruce 5 . Para ésta, Eguiara se basa en la Vida de Calleja - y aprovecha un poco a Castorena-, pero se muestra ufano de poder añadir algunos detalles procedentes de una fidedigna tradición oral.

4 ) Sigue, en orden cronológico, el gran sucesor de Eguiara, o sea José Mariano Beristáin de Souza, cuya Biblioteca hispano-americana septentrional, escrita en español y no en latín, fue impresa dos veces en el siglo xIx (México, 1816-1819, y Amecameca, 1883). El artículo "Cruz (Sor Juana Inés de la)" es más compendioso que el de Eguiara, pero está fundado igualmente en la Vida de Calleja.

Los dos patriarcas de la Bibliografía mexicana cumplen bien su cometido: cuentan "lo que se sabe" de Sor Juana y dan noticia de sus obras, aunque sin meterse en dibujos, es decir, sin emitir juicios literarios, no sólo porque éstos pertenecen a la esfera de lo subjetivo, sino sobre todo porque habría salido muy mal parada la escritora si ellos hubieran dicho lo que sentían de sus versos ${ }^{6}$.

En 1819, o sea el año mismo en que acabó de imprimirse el tercer tomo de la Biblioteca de Beristáin, tuvo Sor Juana su quinta entrada en una enciclopedia. Dos circunstancias hacen de esta entrada algo especial. En primer lugar, la enciclopedia en cuestión es de carácter eminentemente "europeo" (empresa de la Francia napoleónica), pues se trata de la inmensa Biographie universelle publicada por los libreros Michaud frères. (El tomo 1 se había impreso en 1811. El

${ }^{5}$ Los Prólogos, edición y traducción española de Agustín Millares Carlo, se imprimieron en 1944. La "ficha" Ioanna Agnes a Cruce se había publicado en 1936: Vida de Sor Juana Inés de la Cruz, traducción (muy deficiente) de Demetrio Frangos, introducción de Ermilo Abreu Gómez. Una edición reciente de esta "ficha”, en latín y con buena traducción, puede verse en José QuiÑones Melgoza, "Sor Juana: una figura a través de tres siglos", LMM, 6 (1995), 520-549.

${ }^{6}$ Dice Eguiara: "Iam vero ut ad eius scripta veniamus, omnia ferme rogatam fecisse ipsa testatur, vixque praeter opusculum cui nomen dedit Somnium sua sponte aliud elucubrasse”. Es su única mención del Primero Sueño, tan cubierto de elogios por el P. Calleja. En cuanto a Beristáin, cuando llega el momento de decir algo sobre los versos de Sor Juana, lo que hace es citar el juicio del P. Feijoo, y no todo, sino únicamente estas negativas palabras: "aunque su talento poético es lo que más se celebra, fue lo menos que tuvo", lo cual sucedió - añade Beristáin- porque Sor Juana "siguió el gusto de su siglo". De haber nacido antes, sería émula de fray Luis de León y de Esteban Manuel de Villegas; de haber nacido después, se hombrearía con Meléndez Valdés, con Leandro Fernández de Moratín y con José María Vaca de Alfaro (!). Beristáin es ya lo que aún no era Eguiara: un neoclásico hecho y derecho. (Ésta es, según creemos, la razón por la cual el muy neoclásico P. Alegre se abstuvo de nombrar una sola vez a Sor Juana.) -Probablemente la raza de los lectores de Sor Juana nunca se extinguió del todo. Un contemporáneo de Beristáin, el poeta ANASTASIO DE OCHOA, pone como epígrafe de sus Poesías de un mexicano (New York, 1828) estos versos: "Recibid aquesos rasgos / que en mi rústico talento / fueron de tristeza y ocio / incultos divertimentos", que pertenecen a un romance no famoso ("Ilustre Mecenas mío...”, vv. 29-32) . ¡Eso es haber leído a Sor Juana! 
23, que contiene la letra $L$, donde está la "ficha” de Sor Juana, p. 81, se imprimió en 1819. ${ }^{7}$ En segundo lugar, lo que se dice allí de Sor Juana no coincide sino en raros momentos con "lo que se sabía” hasta entonces. Casi todo lo demás es novedoso, - pero no por erudito, sino por perfectamente novelesco.

Una enciclopedia que da cabida a novelas queda desprestigiada de golpe. Pero obviamente nadie reparó en ello; y, por lo demás, la Biographie universelle era -y siguió siendo durante decenios- una obra muy respetable. No es de extrañar que Narciso Oliva, librero barcelonés dotado de buen olfato mercantil, acometiera la empresa de una traducción española (abreviada). Esta traducción se intitula Diccionario histórico o Biografía universal compendiada. El primer volumen apareció en 1830, y el cuarto (letras $C-D$, donde está, íntegra, la "ficha" de Sor Juana) en 1831.

He aquí el texto original y su traducción (la división en párrafos es nuestra):

LACRUZ (JEANNE-INÈS DE), religieuse qui occupe un rang assez distingué sur le Parnasse espagnol, naquit à Mexico en 1614 .

Son oncle maternel, ecclésiastique instruit, se chargea de son éducation, et seconda les heureuses dispositions de la jeune Inès, qui, à l'âge de seize ans, savait le latin, la rhétorique, la philosophie, et faisait des vers avec une étonnante facilité.

Ces talents, un esprit naturel, rendaient sa conversation aussi aimable qu'intéressante, et faisaient ressortir encore plus sa beauté, qui était peu commune.

Plusieurs jeunes gens des premières familles demandèrent sa main. Jeanne-Inès en distingua un, l'aima, et eut le malheur de le perdre lorsqu'elle allait s'unir à lui par un lien indissoluble. De-
Cruz (Juana Inés de la), religiosa que ocupa un lugar distinguido en el Parnaso español, nació en Méjico en 1614.

$\mathrm{Su}$ tío materno, eclesiástico ilustrado, se encargó de su educación y fomentó la feliz disposición de la joven Inés, que a la edad de 16 años sabía el latín, la retórica, la filosofía, y hacía versos con una admirable facilidad.

Con tales dotes y su ingenio natural hacía su conversación amable e interesante, y hacía resaltar aún más su belleza, que era poco común.

Aspiraron a su mano muchos jóvenes de las primeras familias de Méjico, entre los cuales, como era natural, dio Inés la preferencia a uno a quien amaba, y tuvo la desgracia de perderle cuando iba a unirse a él con lazo indisoluble.

7 Quien primero mencionó esta "ficha” fue MARIe-CécIle BénAssy-Berling, "Sor Juana Inés de la Cruz en Europa”, CLAR, 4 (1995), núm. 2, pp. 220-221. La Biographie universelle - dice ella- "es un monumento que fue leído, copiado, traducido, imitado, en muchos países”. 
puis lors elle ne songea qu'à la retraite, et pour consoler sa douleur, elle se livra de nouveau à l'étude des sciences, et apprit l'histoire et les mathématiques.

Ayant dans son cœur renoncé au monde, elle y resta néanmoins, en considération d'un père et d'une mère qu'elle chérissait tendrement, mais après leur mort, elle entra, en 1668, dans un couvent d'Hiéronymites, où elle vécut vingt-sept ans, qu'elle employa en exercices de piété et en travaux scientifiques. Avant d'embrasser la vie religieuse, Jeanne-Inès distribua aux pauvres une grande partie des biens dont elle avait hérité.

La renommée de son savoir était telle que tous les nouveaux vice-rois qui venaient à Mexico voulaient la connaître: souvent même ils la consultaient sur des affaires graves; et, malgré son goût pour la solitude, elle était quelquefois contrainte de paraître au parloir pour recevoir les visites du vice-roi, de l'archevêque et des principaux personnages de la ville. Deux fois les voix unanimes des sœurs ses compagnes la désignèrent pour leur abbesse; mais son humilité s'y refusa constamment.

Cette digne et estimable religieuse mourut d'une attaque d'apoplexie, le 22 janvier 1695. L'archevêque lui-même l'assista dans ses derniers moments; le vice-roi et toute la cour assistèrent à ses funérailles.

Elle a laissé: Poesias de la Madre Juana Inès de Lacruz, Madrid, 1670. Cet ouvrage a eu plusieurs éditions.
Desde entonces sólo pensó ya en el retiro, y para consolar su dolor se entregó de nuevo al estudio de las ciencias y aprendió la historia y las matemáticas.

Renunciando de corazón al mundo, permaneció en él no obstante, en consideración a sus padres, a quienes amaba tiernamente; pero habiendo quedado huérfana, entró en 1668 en un convento de gerónimas, donde vivió veinte y siete años empleados en ejercicios devotos y en científicas tareas. Antes de abrazar la vida religiosa distribuyó Juana Inés a los pobres una gran parte de los bienes que había heredado.

La fama de su saber era tal, que todos los virreyes que iban a Méjico querían conocerla, la consultaban muchas veces sobre asuntos graves, y a pesar de su apego a la soledad se veía algunas veces precisada a presentarse en el locutorio para recibir las visitas del virrey, del arzobispo y de los principales personages de la ciudad. Por dos veces el voto unánime de las monjas sus compañeras la nombraron abadesa, y dos veces con su humildad reusó admitir este cargo.

Esta digna y estimable religiosa murió de un ataque de apoplegía en 22 de enero de 1695. El arzobispo en persona la asistió en sus últimos momentos, y el virrey y toda la corte concurrieron a sus funerales.

Se publicaron en Madrid sus obras en un tomo en 1670, bajo el título de Poesías de la Madre Juana Inés de la Cruz, y consecutivamente se han hecho varias ediciones de este libro. 
La sœur Jeanne-Inès a traité avec succès tous les genres de poésie héroïque; elle excellait surtout dans les Sixains et le Sonnet. Ses poésies sont partagées en sacrées et profanes: parmi ces dernières, on ne trouve cependant aucune composition amoureuse. On distingue dans toutes une verve inépuisable, de la grâce, de la chaleur et une sensibilité exquise.

Tant que sœur Jeanne-Inès suivit les bons modèles, comme Garcilaso, Boscan, etc., elle pouvait être mise à côté des meilleurs poètes espagnols; mais dans la suite, elle se laissa gagner par le mauvais goût de Gongora, et malheureusement elle ne l'imite que trop bien: mais ce défaut même est souvent effacé par des beautés d'un génie supérieur. B-s.
Esta célebre mejicana ha cultivado con acierto todos los géneros de poesía heroica, sobresaliendo particularmente en las sestillasy el soneto. Sus poesías están divididas en sagradas y profanas, siendo muy de notar que entre estas últimas no se encuentra ni una que sea amorosa. En todas ellas se distingue un numen inagotable, gracia, fuego y una sensibilidad exquisita.

En tanto que sor Juana Inés siguió los buenos modelos como Garcilaso, Boscán, etc., podía ponerse al lado de los mejores poetas españoles; pero después se dejó dominar del mal gusto de Góngora, y desgraciadamente le imitó muy bien; pero aun este defecto se borra algunas veces con bellezas de un genio superior.

El "B-s" que firma el artículo es José Bocous, español residente en París, y autor de varias otras "fichas" sobre personajes hispanoamericanos. Se tiene la impresión de que en el París de esos años logró Bocous, de alguna manera, sentar plaza de hispanoamericanista. Lo que hay de verdad en su escrito se reduce a unos cuantos hechos desnudos: Sor Juana ocupa un lugar distinguido en el Parnaso español; era mexicana; sabía latín y compuso versos; era muy admirada por todos; era bonita; fue monja jerónima durante 27 años; murió en 1695. Todo lo demás ha brotado de la férvida fantasía de José Bocous: Sor Juana nació en 1614, se educó bajo la tutela de un eclesiástico, tío suyo; se vio solicitada por muchos jóvenes de las primeras familias; se enamoró de uno de ellos, que murió en vísperas de la boda; desengañada, se dedicó a las ciencias, a la historia y a las matemáticas, y decidió meterse monja; no lo pudo hacer inmediatamente, obligada como estaba a ocuparse de sus queridos padres (se sobrentiende que era hija única); por fin, en 1668 quedó huérfana - ja la tierna edad de 54 años!-; dio entonces de limosna gran parte de sus bienes y tomó el velo; dos veces las monjas del convento, por unanimidad de votos, la eligieron abadesa, y dos veces ella se negó (poseía la virtud de la humildad). Etc., etc. Lo que más llama la atención es la exactitud de cada detalle: el preceptor fue un tío materno; las obras de Sor 
Juana se imprimieron en un tomo, el año de 1670; la estimable religiosa murió de un ataque de apoplejía el 22 de enero de 1695; y, cosa notable, entre sus poesías profanas no hay ni una que sea amorosa.

No cabe duda: José Bocous era un intrépido inventor, un irresponsable de primer orden, un fresco. Nada más ajeno a él que tomarse la molestia de buscar un ejemplar de la Fama, donde hubiera podido leer la Respuesta de Sor Juana a Sor Filotea y la Vida de Calle$\mathrm{ja}^{8}$. Pero su novela corrió con muy buena fortuna. Y aquí nos topamos con un hecho desdichadamente nada raro: el plagio, la repetición acrítica, en una enciclopedia, de lo dicho por una enciclopedia anterior. (Y en vez de "una enciclopedia" puede decirse "un libro" o "un artículo".) En efecto, la fantasiosa noticia de Bocous, traducida literalmente en el Diccionario de Oliva, fue copiada poco después, de manera casi simultánea, en el Diccionario biográfico de mujeres célebres de Vicente Díez Canseco (Madrid, 1844-1845) y en el Diccionario universal de historia y geografía de Francisco de P. Mellado (1846-1850) ${ }^{9}$.

Díez Canseco no se contenta con copiar, sino que amplifica y "hermosea" el texto cada vez que puede, y hasta añade uno que otro detallito. En el primer párrafo se lee ahora (subrayamos las exornaciones y adiciones): "Cruz, Juana Inés de la, llamada vulgarmente la Monja de México, donde nació el año de 1614, fue escritora distinguida y una de las mujeres que han honrado verdaderamente el Parnaso español"; en el segundo párrafo: "[a los 16 años ya sabía retórica y filosofía], había leído las obras de nuestros primeros poetas y versificaba con una facilidad sorprendente"; en el quinto: "distribuyó entre los pobres la mayor parte [no una gran parte] de los bienes que formaban su patrimonio"; y en el penúltimo: "no se halla una sola [poesía] que sea amorosa; en todas sin embargo se revela el verdadero estro poético y una sólida instrucción". Y termina con la noticia de que "Hugalde y Parra" menciona a Sor Juana como autora de comedias ${ }^{10}$.

${ }^{8}$ He aquí algunas noticias de BÉNASsY, art. cit.: Bocous escribió también las "fichas" sobre el Inca Garcilaso - del cual dice que murió en 1568 (!) - y sobre Simón Bolívar, muy mentirosa; "realmente le gusta inventar", dice ella. (Y ojalá haya pescadores de perlas que aprovechen esta pista.) Lo que se permitió hacer el señor Bocous es tanto más notable cuanto que los artículos de la Biographie universelle ostentan "un respetable número de firmas de primera categoría": la "ficha" sobre el sabio José Celestino Mutis se debe nada menos que a la pluma de Alexander von Humboldt.

${ }^{9}$ Maza desconoce el Diccionario de Mellado, y cita el de Díez Canseco (pp. 364366) por una reedición de México, 1851, dedicada "A las señoras mexicanas".

10 Manuel García de Villanueva Hugalde y Parra, Origen, épocas y progresos del teatro español, Madrid, 1802, se limita a decir (p. 318, nota): "Tampoco han faltado poetisas en nuestra España, [por ejemplo doña María de Zayas, doña Leonor Ramírez de Montalvo y] Sor Juana Inés de la Cruz, llamada vulgarmente la Monja de México, de quien se hallan varias comedias". (Hugalde y Parra fue actor profesional. Su libro lo muestra interesado no sólo en el teatro español, sino en el de todos los países y todos los tiempos.) 
Desde la primera frase (Sor Juana, "llamada vulgarmente la Monja de Méjico”) hasta la última (la mención de Hugalde y Parra), el artículo sobre Sor Juana del Diccionario de Mellado, tomo 2, 1846 ${ }^{11}$, es copia del de Díez Canseco, aunque algo abreviada; no dice, por ejemplo, que el eclesiástico preceptor de Sor Juana fuera tío materno, y omite el maravilloso dato de que Sor Juana no escribió una sola poesía amorosa.

En lugar de plagiar el plagio de Díez Canseco, Mellado hubiera podido plagiar muy ventajosamente una anónima "Biografía" de Sor Juana recién aparecida en Madrid en el Semanario Pintoresco Español, tomo 10 (1845), pp. 12-13. Para los tiempos que corrían, esta revista no era desdeñable, y la "Biografía", basada en la Vida de Calleja y en la Respuesta a Sor Filotea, es bastante exacta, si bien entrevera algunos fantaseos, como el de que "a esta joven galana y discreta no era posible que faltasen adoradores, así es que se le ofrecieron buenos partidos" (pero aquí no hay muerte del joven que a punto estuvo de ser su marido). Es posible que Mellado no haya conocido esa "Biografía" ${ }^{2}$, pero también es posible que sí la conociera y que, incapaz de juzgar, eligió a ciegas lo que le pareció más serio (puesto que constaba en un Diccionario). Después de todo, ¡qué más daba! ¿Quién iba a ponerse a averiguar si eso era realidad o fantasía? Recordemos que Sor Juana no tenía lectores. Y no había sorjuanistas.

La famosa historia de la literatura española de George Ticknor se publicó tres años después del Diccionario de Mellado. Dueño de una enorme biblioteca, Ticknor tiene que haber hojeado las obras de Sor Juana, pero lo hizo muy rápidamente, sin concederles ninguna im-

${ }^{11}$ En el mismo año en que apareció este artículo se publicaba el libro de AdoLPH Friedrich VON SCHACK, Geschichte der dramatischen Literatur und Kunst in Spanien, Berlin, 1845-1846, en cuyo t. 3, pp. 419-420, hace el autor, por vez primera, una apreciación del Divino Narciso, remitiendo al tomo de Poemas de Sor Juana, ed. de Barcelona, 1691. Nada parecido sucedía en el mundo cultural de lengua española.

${ }^{12}$ La conoció Ticknor, como luego se verá. Pero ni Ticknor ni nadie, que sepamos, se dio cuenta de que lo publicado en el Semanario Pintoresco fue un plagio descarado del artículo "Juana Inés de la Cruz" que había aparecido en las pp. 329-335 del tomo segundo (1837) de El Mosaico Mexicano, una de las aventuras culturales del impresor Ignacio Cumplido. En El Mosaico el texto va seguido de las liras "Amado dueño mío..." y de las redondillas "Hombres necios...", y acompañado de un retrato, "copia exacta del que se conserva en el convento de S. Gerónimo de esta ciudad" (reproducido por Aureliano TAPIA en su Carta de Sor Juana Inés de la Cruz a su confesor. Autodefensa espiritual, El Troquel, Monterrey, NL, 1993, p. 241), -frase que pasó tal cual al Semanario Pintoresco, donde también hay retrato, pero una sola muestra del talento poético de Sor Juana (el "Hombres necios...", por supuesto). El texto original puede verse en MAZA, pp. 347-358. -El libro-compilación de Francisco de la Maza nos ha sido muy útil, pero creemos muy oportuno hacerles una advertencia a los investigadores que acudan a él: deben estar preparados para hallar errores, datos incompletos, interpretaciones torcidas; y también omisiones: faltan en él la Biographie universelle, el Diccionario histórico de Oliva y el Diccionario universal de Mellado; falta también el dato del Semanario Pintoresco Español. 
portancia. Si acaso leyó el fantástico artículo de Bocous (en el original o en traducción), no le hizo caso. Por lo demás, lo que dice de Sor Juana es casi nada. En una nota de pie de página amontona nombres de poetas insignificantes que vivieron en tiempos de Carlos II, entre ellos Antonio de Solís (a quien considera una especie de tuerto en país de ciegos), y al final estampa este comentario: "Of the persons mentioned in this note, the one that produced the greatest sensation, after Solís, was Inez de la Cruz, - a remarkable woman, but not a remarkable poet [eco del P. Feijoo], who was born in Guipuzcoa in 1651 , and died in the city of Mexico in 1695". A continuación da una única referencia bibliográfica: la noticia anónima aparecida en 1845 en el Semanario Pintoresco Español ${ }^{13}$. Pero ni aquí ni en otro lugar alguno se dice esa cosa extrañísima: que Sor Juana nació ¡en Guipúzcoa! Teniendo en cuenta que Ticknor, a diferencia de Bocous, era un gran erudito, esas líneas dedicadas a Sor Juana son señal aún más elocuente del velo de olvido que había caído sobre ella.

Así como el norteamericano Ticknor es el primero que escribió una historia de la literatura española en toda forma, así el sudamericano (argentino) Juan María Gutiérrez es el primero que en los tiempos modernos escribió un verdadero estudio sobre Sor Juana. Gutiérrez da señales de haber leído los tres tomos de la monja, si bien a veces se permite un poco de "excursionismo"14. Lo que hace en el comienzo mismo de su estudio es proclamar el americanismo de Sor Juana y expresar indignación contra ciertos "libros europeos" a causa de "la

${ }^{13}$ George Ticknor, History of Spanish literature, New York, 1849, t. 2, pp. 549-550.

14 Juan María GutiérRez, Estudios biográficos y críticos, Buenos Aires, 1865, pp. 149204. He aquí un ejemplo de "excursión": a la edad de ocho años, Juana Inés fue llevada por su madre a México y, "previo acuerdo entre el abuelo y los deudos, la colocaron bajo la dirección del bachiller Martín de Olivas, maestro de gramática latina” (p. 132). Y he aquí otro (pp. 183-184). Después de hablar de los letrados de la Nueva España, cuenta Gutiérrez lo siguiente: "Un día, en la capital de Méjico, la jente que acabamos de describir dividióse en dos bandos con motivo de cierto sermón del Mandato, escrito por el padre Paravicino, que leían por primera vez en el seno de una tertulia. El orador exajeraba tanto en él su suficiencia y su petulancia, que no pudo menos que chocar a alguno de sus mismos admiradores. Levantaron éstos una bandera de oposición al gran maestro, y, escandalizados con este acto de insubordinación los que ni siquiera manchas podían admitir en el sol de la elocuencia, trabóse batalla descomunal, a la que proporcionó las armas y proyectiles el arsenal inmenso de la controversia teolójica. En este conflicto de los talentos mejicanos, cada caudillo quiso traer a sus filas el mayor número de secuaces, y ambos se disputaron el parecer de la famosa monja aislada en el convento de San Jerónimo. Sor Juana se hizo poco de rogar..., [y] produjo en pocos días esa obra que con título de Crisis sobre un sermón ha llegado hasta nosotros, en el segundo tomo" de sus obras. El título con que aparece en este segundo tomo es Crisis sobre un sermón de un orador grande entre los mayores, y, como en ningún lugar de la Crisis escribe Sor Juana directamente el nombre del P. Vieira, Gutiérrez concluyó que el gran orador aludido era el célebre español fray Hortensio Félix Paravicino y Arteaga. De haber consultado la Respuesta a Sor Filotea, no hubiera cometido el error. (También Juan María Gutiérrez falta en MAzA.) 
intención o la ignorancia con que insist[en] en arrebatar a la América la gloria de haber dado cuna a Sor Juana Inés de la Cruz":

Varios alemanes eruditos se han empeñado en hacerla vizcaína de nacimiento al ilustrar con biografías las diversas y curiosas colecciones de poesías españolas que han dado a luz. Igual error han cometido también los peninsulares, y, en estos últimos tiempos (en 1845), los redactores del Semanario Pintoresco, periódico de reputación y de gran número de lectores. Pero lo que causa verdadera y justa extrañeza es que haya caído en esta equivocación [un George Ticknor, el cual] dice terminantemente que [Sor Juana] "nació en Guipuzcoa". ¿Cómo pudo cometer este error... [etc.]? Y ya que el escritor orijinal incurrió en esta falta histórica, era deber de sus traductores y adicionadores rectificarle en este pasaje, ya que entre esos traductores se encuentra uno de los más eruditos de España... Válgales a uno y otros por descargo la escasez que siempre se notó en España de los libros, aun los impresos allí mismo, que tienen relación con cosas de América.

No sabemos quiénes son los eruditos alemanes que hacen nacer a Sor Juana en Guipúzcoa. Los que hemos mencionado -Buchholz, Bouterwek, von Schack - la llaman mexicana, lo mismo que Böhl de Faber, que parecería ser el aludido por su "curiosa colección de poesías españolas"15. La noticia de Gutiérrez no parece explicable (la "Biografía" del Semanario Pintoresco comienza así: "Nació... en el pueblo de San Miguel Nepantla, cerca de Améca-Améca”). Mientras no se demuestre otra cosa, el error pertenece no a unos alemanes sino a Ticknor, el cual seguramente leyó de prisa la Vida del P. Calleja, donde se menciona la "vizcainidad" (falsa, además, según toda evidencia) del padre de Sor Juana. En todo caso, el mayor reproche de Gutiérrez va lanzado, y con muchísima razón, contra los traductores y adicionadores (en cursiva) de Ticknor, en especial contra el respetadísimo Pascual de Gayangos, eminente bibliógrafo y gran autoridad. La observación de Gutiérrez tiene un doble significado: primero, durante el siglo XIX - iy aun en el xx! - los eruditos españoles dieron en efecto copiosas muestras de desinterés por las cosas de "nuestra América"; y segundo, el hecho de que a un Gayangos no le llamara la atención el disparate de Ticknor es una indicación aplastante de que Sor Juana y sus coetáneos eran tan poca cosa para el erudito norteamericano como para los eruditos españoles ${ }^{16}$.

15 Juan Nicolás BöHl de Faber, Floresta de rimas antiguas castellanas, Hamburgo y Leipzique, 1821-1825, t. 3, núms. 854 y 926. En nota al núm. 854 ("Hombres necios...") Böhl llama a Sor Juana "mexikanische Nonne".

${ }^{16}$ Historia de la literatura española, por M. G. Ticknor..., traducida al castellano, con adiciones y notas críticas, por D. Pascual de Gayangos y D. Enrique de Vedia, Madrid, 1851-1856, t. 3, p. 232: “...quien más sensación causó después de Solís, fue Sor Juana Inés de la Cruz, más notable como mujer que como poeta; nació en Gui- 
Los avatares de la fantasía de Bocous no han terminado aún. BÉNASsY, art. cit., dice que la "ficha" de Sor Juana "se repite sin la menor corrección en la segunda edición" de la Biographie universelle (letra $L, 1850)^{17}$, y seguirá aprovechándose en el mundo de habla española. Así en el Diccionario de biografia universal publicado bajo la dirección de Juan Sala en Madrid, 1862. Y es curioso comparar este aprovechamiento con el de Díez Canseco. El redactor de la ficha "Cruz, Sor Juana Inés de la" en el Diccionario de Juan Sala dejó en los puros huesos el artículo original (abreviamos a nuestra vez la cita, pero sólo un poco):

Poetisa española, llamada vulgarmente la Monja de Méjico. N[ació] en Méjico en 1614, según otros en Guipuzcoa en 1651, y murió en Méjico en 1693. Estudió... bajo la dirección de un tío suyo, y tomó el velo... de resultas de una pasión desgraciada... Sus poesías, que comprenden todos los géneros heroicos, en que sobresalen principalmente los sestillos y el soneto, se publicaron en un tomo y se dividen en sagradas y profanas $^{18}$.

Aquí se merece un lugar Emilio Pardo. En 1853-1856 se imprimió en México una adaptación del Diccionario de Mellado realizada "por una sociedad de literatos distinguidos, y refundida y aumentada con-

púzcoa en 1651", etc. -JUAN LEÓN MERA, el otro gran pionero del sorjuanismo moderno (Obras selectas de la célebre monja..., Quito, 1873), se escandaliza también por el error de Ticknor.

${ }^{17}$ A estas dos ediciones sucedió en 1860 una Nouvelle biographie universelle, cuya "ficha" La Cruz (Juana-Inés de) es brevísima: "poétesse espagnole, née dans le Guipuzcoa en 1651. Elle reçut une éducation soignée, et entra dans un couvent de hiéronymites. Elle semble avoir été une femme d'un grand mérite; mais, au jugement de M. Ticknor, son talent poétique était peu remarquable. Ses poésies ont eu cependant plusieurs éditions; elles parurent sous le titre de Poemas de la Madre Juana-Inez de la Cruz, la décima Musa, Saragosse, 1682-1725, 3 vol. in-4º. Ce volumineux recueil contient des poésies lyriques (sixains, sonnets, etc.) et des drames". Aunque se cita bibliografía "de actualidad" (el artículo del Semanario Pintoresco y la History de Ticknor), quedan vestigios del artículo de Bocous, como lo de la "éducation soignée" y el dato de que Sor Juana sobresalió en sus sixains y sus sonnets. (Estos sixains, o sextillas, son obviamente los tres poemas en liras de 6 versos que hizo Sor Juana.)

18 Véase el texto completo en MazA, p. 391. En el prólogo declara Juan Sala que los redactores de su Diccionario se han basado en "los mejores libros, estudios, historias y crónicas". El redactor de esta breve noticia debe de haber estado en aprietos al ver que "los mejores" estudios sobre Sor Juana eran tan incompatibles en cuanto a lugar y fecha de nacimiento. (El año de muerte, 1693, tiene que ser simple errata de imprenta.) -Según parece, es ésta la última vez que se da como fecha de nacimiento el año de 1614. Pero el nacimiento en Guipúzcoa continúa vigente durante un tiempo más: en el resumen histórico que forma parte de los Principios generales de literatura española de MANuel de la Revilla, Madrid, 1872, su colaborador Pedro DE Alcántara García, después de mencionar a varias escritoras, añade: "No es digna de menos mención la monja peruana [!], natural de Guipúzcoa, Sor Juana Inés de la Cruz, a quien por su facilidad y gallardía en la versificación dieron el sobrenombre de Musa décima" (citamos por la $4^{\underline{a}}$ ed., Madrid, 1898, t. 2, p. 439). 
siderablemente para su publicación en México”. Se trata de una obra de bastante altura (como que entre esos literatos están hombres de la talla de Lucas Alamán, García Icazbalceta, José María Andrade y Orozco y Berra). Y lo confirma brillantemente el hecho de que uno de los redactores, Emilio Pardo, prescinda por completo de lo que sobre Sor Juana decía el Diccionario de Mellado (o sea lo fantaseado por Bocous) y haya escrito un artículo sólido, basado inteligentemente en la Respuesta a Sor Filotea y en la Vida de Calleja, y sembrado de reflexiones personales ${ }^{19}$. Pardo, por lo demás, da muestras de haber leído (y gozado) varias poesías de Sor Juana, lo cual viene a confirmar lo que dijimos al final de la nota 6. La reacción de Emilio Pardo contra el enciclopedismo estúpido es parecida a la de Carrillo y Pérez (supra, p. 106) contra los dogmas del neoclasicismo ${ }^{20}$.

Los fantaseos de Bocous reaparecen en el Diccionario biográfico americano de José Domingo Cortés, cuyo artículo "Cruz, Sor Juana Inés de la" es copia fidelísima del aparecido en el Diccionario de Mellado, aunque, como suele suceder, Cortés calla esta fuente. Su Diccionario apareció en París en 1875²1, de manera que es posterior a los estudios de Juan María Gutiérrez (1865) y de Juan León Mera (1873).

El último avatar de los fantaseos de Bocous parece ser el artículo "Cruz (Sor Juana Inés de la)" del Diccionario enciclopédico hispano-americano (1887-1898) publicado en Barcelona por la casa Montaner y Simón. El redactor acepta esos fantaseos, tomándolos del artículo de José Domingo Cortés que acabamos de mencionar, aunque a veces se atreve a intervenir: "El biógrafo americano José Domingo Cortés

${ }^{19}$ Una conjetura como ésta acerca de la familia de Sor Juana: "probablemente estaba organizada con la austera piedad y con aquella mezcla de severidad y amor... que caracterizaban a las familias antiguas" podrá parecernos inexacta aparte de ingenua, pero no es un fantaseo irresponsable. Tampoco es loca esta otra conjetura: Sor Juana, lectora nada vulgar, debe de haber sentido muy intensamente las pasiones expresadas en las comedias de Lope y Calderón; quizá estuvo enamorada romántica, juvenilmente; quizá "su repentina vocación [monástica] reconoció por origen alguna ilusión desvanecida...”, etc.

${ }^{20}$ El texto de Pardo está en MAzA, pp. 368-379. (Tal vez haya un eco de Ticknor en esta apreciación suya: "mujer por mil títulos célebre, y acaso, más que por sus obras..., por su vida íntima”.) -La biografía de Sor Juana por TADEO ORTIz en su México considerado como nación independiente, de 1832 (MAZA, pp. 343-347), tampoco tiene que ver con el artículo de Bocous (quizá Ortiz no llegó a conocerlo); se basa en Calleja y en Beristáin.

${ }^{21}$ Entre 1871 y 1875 se imprimió una buena docena de libros suyos (parte en Chile, parte en París). Su campo preferido era la historia y literatura en Bolivia, Chile y el Perú. (Los tres primeros títulos que figuran en PALAU, Manual del librero, s.v., parecen ser de un homónimo: son tres alegatos jurídicos impresos los tres en Montevideo, 1862.) El texto del Diccionario puede verse en MAZA, pp. 516-517. Hay una sola discrepancia con el texto de Mellado: éste dice "Por dos veces el voto unánime de las monjas... la nombraron abadesa"; Cortés corrige el anacoluto (anotándose un punto a su favor): "Dos veces, por el voto unánime de las monjas..., fue nombrada abadesa". 
dice que la famosa poetisa nació en 1614; pero merece más crédito el padre Diego Calleja...”, etc. A lo largo del artículo entremezcla las dos autoridades, como si estuvieran en el mismo nivel: Juana leyó los libros del abuelo materno; "muertos sus padres, distribuyó a los pobres su patrimonio...; todos los virreyes querían conocerla...; en dos ocasiones fue elegida abadesa"; sus Poesías se publicaron en Madrid, 1670, en un volumen...”. ¡Notable perduración del artículo de Bocous, publicado setenta años antes, y hecho todo de imaginaciones y mentiras, o sea de humo! ${ }^{22}$.

De los fantaseos de Bocous, el que tuvo más arraigo fue el de los melancólicos amores de Juana Inés. Claro que este fantaseo puede haber brotado, independientemente, de la cabeza de cualquier crítico o aun simple lector: Sor Juana pudo ser solicitada de amores, pudo haberle sonreído a algún apuesto joven, pudo sufrir una decepción, etc. ${ }^{23}$. Emilio Pardo dice que la joven Juana Inés fue "dama de honor de la virreina esposa del conde de Paredes D. José de la Cerda, marqués de la Laguna" ${ }^{4}$, en cuya corte fue celebrada; "su notable her-

22 Véase MAZA, pp. 553-556. El redactor observa que el P. Calleja no dice nada de los "amores" de Juana Inés. Al final cita el juicio de Mesonero Romanos en el t. 49 de la $B A E$ (cf. MAZA, pp. 388-389) y dice que en ese tomo, y también en el 42, hay cosas de Sor Juana.

23 Menéndez Pelayo (1893) fue el gran consagrador de la idea; entre los obstáculos que tuvo que vencer Sor Juana está "el amor humano que tan hondamente parece haber sentido, porque hay acentos en sus versos que no pueden venir de imitación literaria”. -También corrió con cierta fortuna el cuento de que dos veces las monjas nombraron "abadesa" a Sor Juana. Lo acepta todavía un investigador tan serio como Ezequiel A. Chávez (1931). Méndez Plancarte, en su ed. de Sor Juana, t. 1, p. lx, nota 49, declara no conocer el origen de semejante noticia, y observa: "Sería, en todo caso, priora, como llamábase la de S. Jerónimo”.

24 Curiosa confusión con el marqués de Mancera. (Por lo demás, el de la Laguna no se llamaba José, sino Tomás Antonio.) Aprovechamos el momento para exhibir una muestra más de aceptación mecánica de los errores impresos: MARCos Arróniz, Manual de biografía mejicana, París-New York, 1857, s.v. "Cruz", dice que Juana fue "nombrada dama de honor de la virreina esposa del conde de Paredes D. José de la Cerda, marqués de Laguna”. -Quizá valga la pena someter a crítica la afirmación de que Juana fue "nombrada dama de honor". De ello no hay constancia alguna. En la Vida del P. Calleja, fuente única para esta etapa, se lee que los "parientes" de Juana "la introduxeron" en el palacio de Mancera. La traducción es: 'le consiguieron un lugar en la servidumbre de palacio'. Claro que inmediatamente los virreyes, "viéndola que acertaba, como por uso [¡como si ya estuviera acostumbrada!], en quanto, sin mandárselo, obedecía", se encariñaron con ella, y la virreina "no parece que podía vivir un instante sin su Juana Inés”. Si descontamos el normal tono hiperbólico de Calleja, nos quedamos con un hecho claro: Juana entró en el palacio como criada, no como "dama de honor". Sor Juana comenzó desde muy abajo, y esto es lo que debería destacarse. -Algo parecido sucede con los fantaseos acerca de la situación socio-económica de la familia. Marcos ArRónIz, por ejemplo, dice (loc. cit.) que los padres de Juana "poseían bastantes bienes y un puesto distinguido en la sociedad”. Si se trata de engrandecer a Sor Juana, más la engradece el no haber nacido entre sábanas de Holanda. 
mosura, su celebridad y las costumbres galantes de los últimos años del reinado de Felipe IV debieron poner a prueba la vocación religiosa a que se consagró después”.

La antítesis entre una corte pululante de amoríos y un riguroso retiro monástico era una idea irresistible. Siguiendo a Pardo - y recargando las tintas-, Marcos Arróniz dice en 1857: "Esa corte era un remedo en galantería de los últimos años del reinado de Felipe IV, y aquellas costumbres un poco licenciosas debieron poner a prueba y acrisolar después la virtud de nuestra poetisa, que mil veces se vería atacada por el amor impetuoso y la insinuante lisonja, a que servirían como imán poderoso su cabal belleza y su agudo talento... Se ignora si alguna pasión desvanecida, o esa tristeza vaga sin nombre en la vida...", etc., la llevó a "buscar refugio en el silencio del claustro"25.

Lo propio del "sello Bocous" es convertir sin más las hipótesis en otras tantas seguridades. Así - aunque no dependa de Bocous- el citado artículo del Semanario Pintoresco (1845): a Juana "se le ofrecieron buenos partidos, solicitando su mano con empeño hombres distinguidos". Adolfo de Castro, fantaseador de primera, da como un hecho los amores de Juana y hace una atrevida conjetura en cuanto al objeto de ellos: "Quizá sea [el marqués de Mancera] el Fabio a quien ella dedicó muchas de sus poesías, como a su tierno amante [!]. Pero algún gran inconveniente o algún no menos grande desengaño tuvo ella en sus amores...", etc. ${ }^{26}$ Juan León Mera dice que varios autores "aseguran que la resolución de nuestra heroína fue causada por la muerte del joven con quien iba a casarse", y añade: "Nuestra opinión concuerda bastante con ésta...: que hubo muerte, ausencia o pérdida del amante... es un hecho más que probable"; "Juana abrigaba una pasión, de esas vehementes, violentas, consumidoras pasiones que prenden sólo en el pecho de las poetisas formadas por el amor y para el amor”, etc. (¡una Juana de Ibarbourou!) 27. Como últi-

25 Marcos Arróniz, Manual de biografía mejicana, París-New York, 1857, pp. 133134, idea desarrollada en su Manual del viajero en México, París, 1858 (apud MazA, pp. 382-385): "Se ignoran las causas que la decidieron a cubrir su esbelto cuerpo con el sayal de monja, cuando su posición elevada en la corte, sus cuantiosos bienes y sus muchos méritos le prometían en el mundo una cadena no interrumpida de triunfos". Y recoge de Pardo la idea de que la joven Juana, dotada de "imaginación de fuego y sensibilidad exquisita", debe de haber vivido existencialmente los amores de las comedias: “¿Qué! ¿No aguardaría nuestra poetisa ver realizado uno de esos galanes dignos y valientes...?”; pero "su espíritu era elevado", y prefirió encerrarse en el claustro: “iAllí por éxtasis religiosos y por devotas contemplaciones trocó las caricias de juvenil vigor y los besos de ámbar de algún generoso y bello amante!”

26 Adolfo de Castro (ed.), Poetas líricos de los siglos xvi y xvii, Madrid, 1857 (BAE, t. 42), pp. 545-546. (Eso de "algún gran inconveniente" quiere sonar misterioso y resulta muy cómico. Dan ganas de recordarle a don Adolfo que Mancera era casado.)

27 Pese a su propósito de atenerse a las fuentes originales, Mera no puede prescindir de fantaseos que parecen ya como "consagrados por el uso". La repartición de bienes antes de la entrada en el convento "y el haber esperado que muriesen sus 
ma muestra, he aquí una frase de Francisco Sosa (1874): "Antes de entrar al convento habían resonado en el corazón de Sor Juana las palabras que dicta el amor; sus ojos se habían abrasado con la luz de otros ojos; su alma había soñado con otra alma" 28 .

Ante afirmaciones como éstas no cabe sino un comentario: las posibilidades novelescas de los "amores" de la hermosa y discreta Juana, dama de honor de la virreina, perla de la corte, eran irresistibles. (¿Quién que es no es romántico?)

Lo dicho hasta aquí no carece de moraleja: hay que mantener los ojos bien abiertos cuando se publica una novedad acerca de Sor Juana; no hay que dejar que la facultad crítica se entumezca. Pensamos, concretamente, en cosas ocurridas durante los últimos veinte años. En buena crítica, es imposible que la Carta de Sor Juana al P. Núñez sea espuria. Pero las novedades que más abundan son de otro género. He aquí algunas: que el Primero Sueño se escribió bajo la influencia del Somnium Scipionis de Cicerón, y que narra un viaje por "los espacios siderales"; que Sor Juana estuvo todo el tiempo en guerra con el patriarcalismo y la falocracia, como se comprueba una vez que la crítica feminista ha descifrado la "clave" que la monja se vio forzada a usar para poder expresarse; y que Sor Juana, incansable lectora del P. Kircher, estaba metidísima en la tradición hermética ${ }^{29}$. Los expo-

padres" le parecen cosas "evidentes". Acepta también la noticia de que Juana tuvo como preceptor a "un respetable sacerdote, su tío"; y repite que "dos veces fue electa abadesa, y ambas renunció decididamente".

28 Francisco Sosa, "Discurso" en la velada del Liceo Hidalgo (1874), apud MAZA, p. 483. -Unos años antes, el Grand Dictionnaire Universel du XIXe Siècle (de Larousse) dice con toda naturalidad que Juana Inés "s'était vue plusieurs fois recherchée en mariage, autant par ses qualités morales que par son talent et sa beauté". Pero lo que hay de sensacional en este Larousse es otra cosa: "à l'âge de douze ans elle parvint à décider son père à la conduire à Mexico et lui permettre de s'habiller en garçon pour pouvoir assister aux cours de l'Université qui venait d'être fondée [ien 1663!] dans cette ville. Elle y apprit la langue latine...”, etc.: citado por MAzA, p. 392. (Con razón era Sor Juana tan sabia: ¡se formó en la Universidad de México!)

29 Véase A. Alatorre, "Lectura del Primero Sueño", en "Y diversa de mí misma / entre vuestras plumas ando": Homenaje Internacional a Sor Juana Inés de la Cruz, ed. Sara Poot, El Colegio de México, 1993, pp. 101-126. El mismo Alatorre, "Avances en el conocimiento de Sor Juana", en Conquista y contraconquista: La escritura del Nuevo Mundo. (Actas del XXVIII Congreso del Instituto Internacional de Literatura Iberoamericana), eds. Julio Ortega y José Amor y Vázquez, El Colegio de México-Brown University, 1994, pp. 663-664, dice su opinión sobre "un libro publicado en 1980 con el prometedor título de El hermetismo y Sor Juana Inés de la Cruz": "Lo encontré muy entretenido; es toda una batalla campal entre Octavio Paz, por un lado, y Elías Trabulse, Jorge Alberto Manrique y Edmundo O'Gorman, por el otro. Los lances protagonizados por Paz y O'Gorman, cada uno a su modo, son para mí los mejores. Pero eso es todo. El avance en cuanto a conocimiento de Sor Juana no lo veo por ningún lado. Sabíamos, antes de la polémica, que algunas noticias tenía Sor Juana acerca del P. Athanasius Kircher. Y allí, justamente allí, es donde nos quedamos una vez leída la espectacular 
sitores de estas novedades han visto aceptados y aplaudidos en proporción variable sus respectivos hallazgos. ( $\mathrm{Si}$ tal aceptación va a durar lo que duró la fantasía de Bocous, está por verse.) La novedad más reciente (1995) es el descubrimiento de una obra desconocida de Sor Juana, una Carta firmada con el pseudónimo "Serafina de Cristo", - hallazgo que comienza ya a entrar en el caudal de "lo que se sabe". Pero para esto remitimos a nuestro libro Sor Juana y Serafina de Cristo, recién publicado (1998) por El Colegio de México.

\author{
Antonio Alatorre \\ Martha Lilia Tenorio \\ El Colegio de México
}

polémica. Lo que menos parece importar a los contendientes es aducir pruebas, verdaderas pruebas, de que Sor Juana estaba inserta en la tradición del hermetismo". Mencionemos por último a Francisco López Cámara, que en 1950 salió con la novedad de que Sor Juana fue seguidora de Descartes. (Esta idea parece haber tenido muy pocos partidarios.) 